\title{
Influência da expansão rápida da maxila na rizólise dos caninos decíduos usados como ancoragem
}

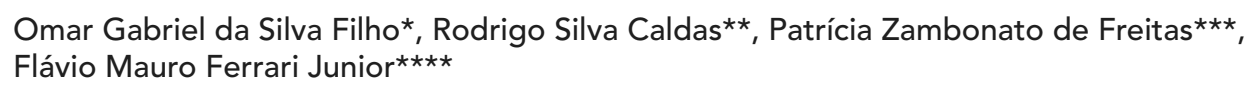

\section{Resumo}

Objetivos: o presente estudo radiográfico, retrospectivo e longitudinal objetivou determinar se a ancoragem do aparelho expansor fixo tipo Haas, modificado para as dentaduras decídua e mista, interfere na velocidade de rizólise e esfoliação dos caninos decíduos. Métodos: foi feita uma avaliação quantitativa da rizólise do canino decíduo mediante a medição do comprimento coroa-ápice dos caninos decíduos superiores, dos lados direito e esquerdo. Para essa avaliação, 24 crianças submetidas à expansão rápida da maxila (ERM) na dentadura decídua ou no início da dentadura mista foram comparadas com 15 crianças que não passaram por esse procedimento. A medição do comprimento coroa-ápice dos caninos decíduos foi realizada com o programa computadorizado CEF-X Cefalometria Digital, produzido pela CDT Informática, que permitiu calibrar o tamanho dos dentes pela uniformização das imagens radiográficas digitalizadas. Resultados: os dados estatísticos revelaram que não houve diferença na velocidade de rizólise dos caninos decíduos entre as crianças do grupo controle e as do grupo submetido à ERM. Conclusões: é possível inferir que o aparelho expansor fixo tipo Haas ancorado em dentes decíduos não influencia a rizólise dos caninos decíduos usados como ancoragem.

Palavras-chave: Expansão maxilar. Má oclusão. Reabsorção da raiz. Ortodontia Interceptiva.

\section{INTRODUÇÃO}

Existe um consenso na literatura e entre os ortodontistas de que a má oclusão não representa uma característica exclusiva da dentadura permanente, estando presente também nos estágios que antecedem a maturidade oclusal. A rigor, a preocupação com a questão se justifica, pois, como regra geral, a má oclusão estabelecida nos estágios precoces do desenvolvimento da oclusão, desde a dentadura decídua, não se corrige espontaneamente. Isso quer dizer que, uma vez estabelecida, a má oclusão não tratada se perpetua até a maturidade oclusal. Conclui-se, portanto, que a má oclusão está presente nos três estágios do desenvolvimento oclusal: dentaduras decídua, mista e permanente.

A deficiência transversal - que deforma o contorno do arco dentário superior, imprimindo-lhe

Ortodontista do Hospital de Reabilitação de Anomalias Craniofaciais - USP / Bauru. Coordenador do Curso de Ortodontia Preventiva e Interceptiva da PROFIS - Bauru.

** Residente do setor de Ortodontia Preventiva e Interceptiva do Hospital de Reabilitação de Anomalias Craniofaciais - USP / Bauru.

*** Ortodontista do Hospital de Reabilitação de Anomalias Craniofaciais - USP - Bauru. Professora do Curso de Ortodontia Preventiva e Interceptiva da PROFIS - Bauru.

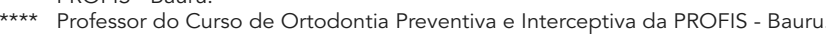


uma morfologia mais triangular - representa um problema comum entre as más oclusões, independentemente do estágio do desenvolvimento oclusal. Tem indicação de tratamento precoce $\mathrm{e}^{15,19,20,23}$, desde a dentadura decídua ${ }^{20}$, a partir dos 5 anos de idade, contanto que a deficiência estabeleça um erro na relação transversal interarcos, representado pela mordida cruzada posterior. Portanto, a mordida cruzada posterior pode ser corrigida desde a dentadura decídua. A expansão rápida da maxila (ERM), na ausência de mordida cruzada posterior, pode ser realizada a partir da dentadura mista, com fins de ganho no perímetro do arco dentário superior ${ }^{1}$ para correção de apinhamento.

O aparelho expansor fixo tipo Haas ${ }^{5}$, de ancoragem dentomucossuportada, representa um instrumento competente para romper as suturas maxilares de forma muito previsível, principalmente em idades precoces ${ }^{20}$, quando a resistência do esqueleto facial é reduzida. No seu desenho, a estrutura metálica une os dentes posteriores do mesmo lado por intermédio de uma barra de conexão, construída com fio de aço inoxidável de
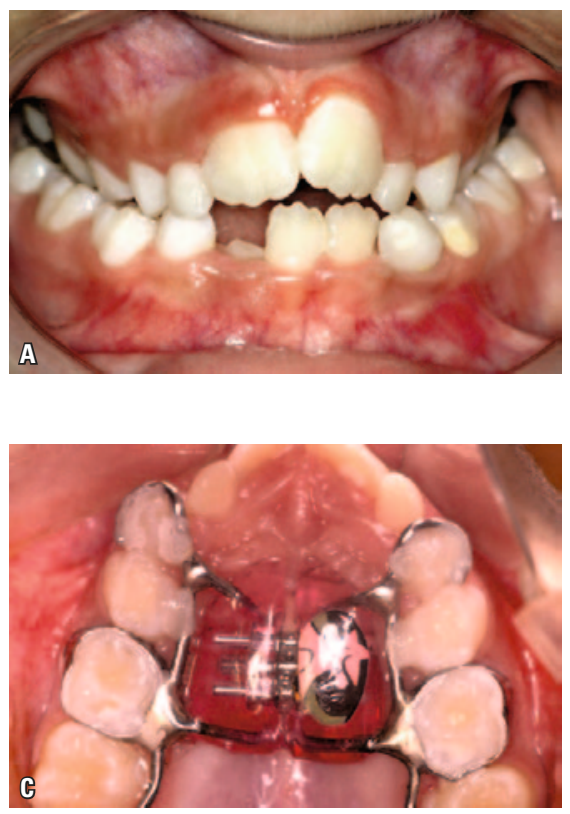

1,2mm de diâmetro. Os dois botões palatinos de resina acrílica que envolvem as barras de conexão de cada quadrante encostam-se ao palato, liberando somente as regiões das papilas gengivais e rugosidades palatinas. Unindo os dois botões de acrílico, o parafuso expansor compreende a parte ativa do dispositivo. A despeito do contato direto dos botões de acrílico com a mucosa palatina, o aparelho expansor tipo Haas não acarreta iatrogenias no palato, pelo menos nos estágios que antecedem a dentadura permanente ${ }^{21}$ (Fig. 1).

Uma vez instalado, o aparelho expansor fixo tipo Haas é apoiado na mucosa palatina e em dentes decíduos, quando nas dentaduras decídua e mista. Os apoios nos caninos e nos segundos molares decíduos beneficiam a ancoragem, mas não se sabe se a força exercida sobre esses dentes, correspondente à resistência esquelética da face média, influencia o processo de rizólise espontânea. Na dentadura permanente, a força gerada pelo acionamento do parafuso expansor pode alcançar de $1.400 \mathrm{~g}$ a $4.500 \mathrm{~g}$ em cada ativação do mesmo, podendo alcançar até $10 \mathrm{~kg}$, por ser acumulativa,
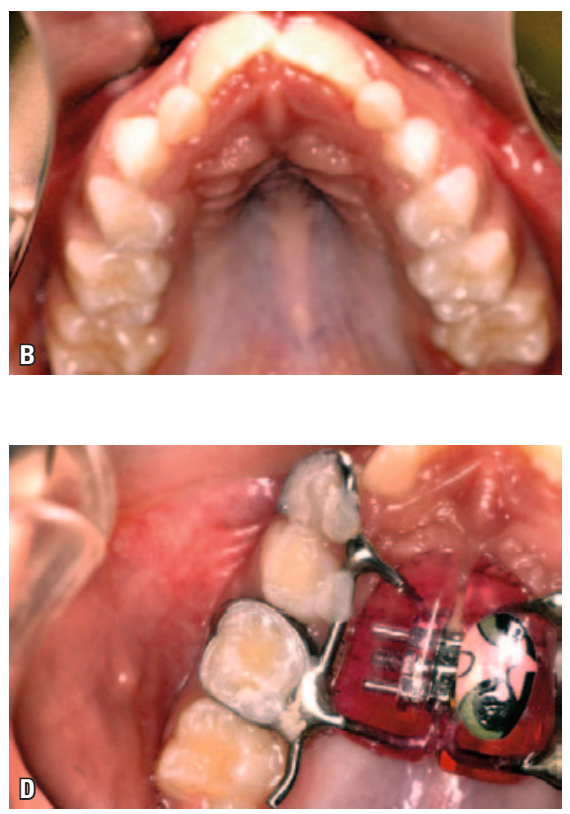

FIGURA 1 - Mordida cruzada posterior (A) resultante da atresia simétrica do arco dentário superior (B). 0 tratamento consiste em aumentar a largura do arco dentário superior com o aparelho expansor fixo tipo Haas modificado (C). A ancoragem metálica inclui dentes decíduos, os caninos e os molares (D). 
na dependência do comportamento esquelético da maxila ${ }^{6}$. O acompanhamento do desenvolvimento da oclusão depois da ERM dá sinal de que os dentes decíduos suportam bem a resistência facial durante a expansão ortopédica da maxila. Apesar dos dentes decíduos receberem o impacto da força, tudo indica que a reabsorção fisiológica não se deixa influenciar pela mecânica ortopédica transversal.

As alterações do complexo dentinopulpar em consequência da movimentação dentária induzi$\mathrm{da}^{7,12,14,16,17,18,27,28}$ e da $\operatorname{ERM}^{7,24}$, bem como as alterações na superfície radicular ${ }^{2,8,24,25,26}$, excitam a reflexão sobre os fatores mecânicos externos que influenciam a rizólise dos dentes decíduos. Tendo isso em mente, o presente estudo pretende analisar a velocidade de rizólise dos caninos decíduos utilizados como ancoragem do aparelho expansor fixo tipo Haas, comparando-a com a da rizólise espontânea desses dentes.

\section{MATERIAL E MÉTODOS}

\section{Amostra}

A amostra total, retrospectiva e longitudinal, foi constituída por 39 crianças de ambos os gêneros, 21 meninos e 18 meninas, cadastradas nos arquivos do Curso de Ortodontia Preventiva e Interceptiva da Profis, em Bauru/SP. A amostra foi dividida em crianças submetidas à ERM (grupo experimental) e crianças que não se submeteram à ERM (grupo controle).

O grupo experimental foi constituído por 24 crianças, igualmente divididas quanto ao gênero, que utilizaram o aparelho expansor fixo tipo Haas na dentadura decídua ou no primeiro período transitório da dentadura mista (início da dentadura mista), de acordo com os seguintes critérios de inclusão: (1) ter utilizado o aparelho expansor fixo tipo Haas modificado (com bandas nos segundos molares decíduos e barra de conexão tangenciando os primeiros molares decíduos e abraçando os caninos decíduos), (2) ter radiografia panorâmica nos seguintes estágios: pré-expansão e bianualmente até a esfoliação dos caninos decíduos, e (3) ser de ambos os gêneros, independentemente da faixa etária, uma vez que a referência de desenvolvimento nesse estudo é a idade dentária.

O grupo controle foi constituído por 15 crianças, sendo 9 meninos e 6 meninas, em estágios desenvolvimentais pareados com as 24 crianças do grupo experimental, porém não submetidas à ERM. No grupo controle, os caninos decíduos não receberam nenhum impacto de mecânica ortodôntica.

O protocolo da ERM consistiu de uma volta completa do parafuso expansor por dia, sendo $2 / 4$ de volta pela manhã e $2 / 4$ de volta à noite (fase ativa da expansão), até a sobrecorreção da mordida cruzada posterior. Finalizada a fase ativa da expansão, o aparelho foi mantido em contenção (fase passiva da expansão) até a completa ossificação da sutura palatina mediana, diagnosticada nas radiografias oclusais de maxila pós-expansão. Em média, a fase passiva da expansão durou seis meses, após o que o aparelho expansor foi removido e, em seu lugar, foi instalada uma placa palatina removível, que funcionava como contenção, por um período que variou de seis meses a um ano.

\section{Métodos}

A avaliação realizada no presente estudo baseou-se em radiografias panorâmicas tiradas desde o final da dentadura decídua ou início da dentadura mista, passando pelos estágios subsequentes da dentadura mista até a esfoliação dos caninos decíduos (Fig. 2, 3). As radiografias panorâmicas foram fotografadas com uma máquina digital Nikon Coolpix 995 em um negatoscópio de luz branca, usando uma mesa estativa previamente calibrada para a obtenção da imagem inteira da radiografia panorâmica. Todas as fotografias foram obtidas usando-se a mesma resolução de imagem (1 megapixeI). Após armazenadas em um computador, todas as imagens foram tratadas e colocadas em escala de cinzas. A resolução de 1 megapixel era necessária para permitir uma boa visualização das 

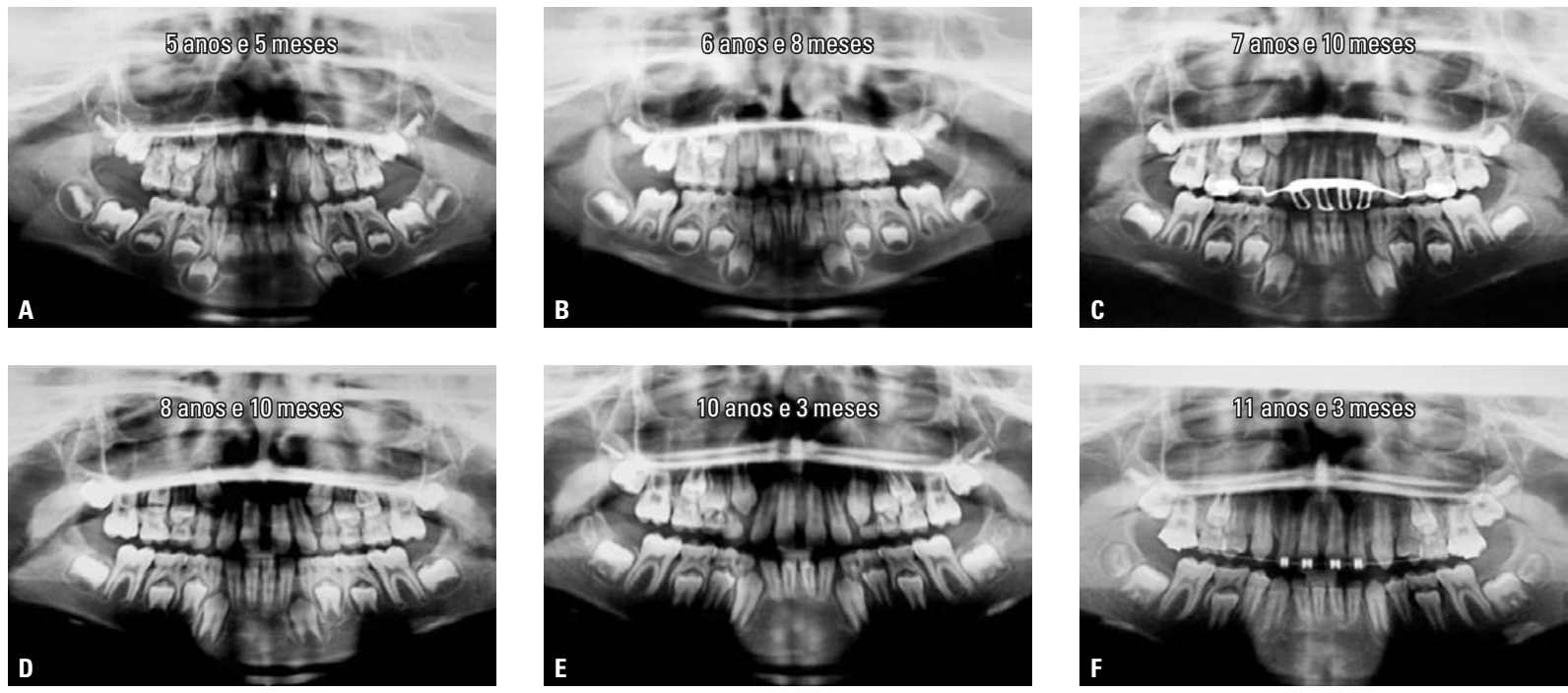

FIGURA 2 - Acompanhamento longitudinal com radiografias panorâmicas de um paciente do grupo controle.
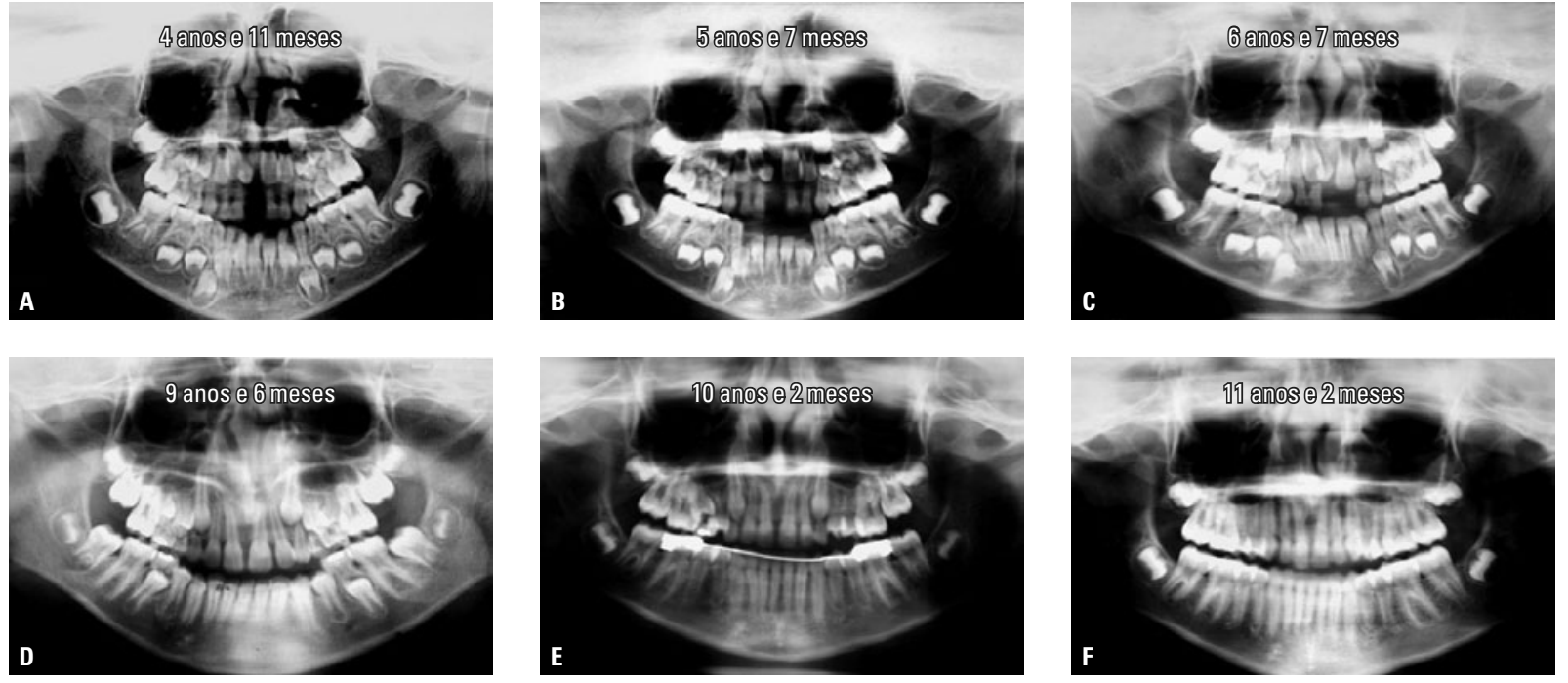

FIGURA 3 - Acompanhamento longitudinal com radiografias panorâmicas de um paciente do grupo experimental.

imagens no monitor do computador ${ }^{25}$.

A área de interesse específico envolvia os caninos decíduos superiores. A gravação das imagens em um computador visou a medição do comprimento coroa-ápice dos caninos dos lados direito e esquerdo, em todas as radiografias panorâmicas, utilizando-se o programa CEF-X Cefalometria Digital, produzido pela CDT Informática
(Cuiabá/MT). O programa permite a calibração do tamanho das imagens pela uniformização das imagens radiográficas digitalizadas.

Os dados correspondentes aos comprimentos dos caninos decíduos foram submetidos ao cálculo da média, do desvio-padrão e do teste "t" de Student, para comparação entre os valores dos grupos controle e experimental. 


\section{RESULTADOS}

As médias, os desvios-padrão e a aplicação do teste " $t$ " de Student para o comprimento coroaápice dos caninos decíduos superiores estão expressos na tabela 1. A disposição das medidas médias do comprimento coroa-ápice, desde antes da expansão até próximo de sua esfoliação, compôs o gráfico 1 .

\section{DISCUSSÃO}

Muito já foi escrito sobre os efeitos mecânicos da expansão ortopédica da maxila, elucidando os comportamentos esquelético e dentário promovidos pelo acionamento do parafuso expansor. No aspecto biológico nem tanto, pois parece consenso entre os estudiosos a reabsorção radicular externa provocada pela mecânica transversal nos dentes de ancoragem ${ }^{2,8,24,25,26}$. A literatura também tem sinalizado com reações inflamatórias pulpares ${ }^{7}$.

Quando aplicado nas dentaduras decídua e mista, o aparelho expansor apoia-se em dentes decíduos, destinados à esfoliação espontânea decorrente da rizólise (reabsorção radicular fisiológica). O processo de reabsorção radicular nos dentes decíduos provavelmente tem sua explicação na apoptose dos cementoblastos e odontoblastos ${ }^{3,9}$, o que explica sua ocorrência mesmo diante da ausência ou da ectopia do sucessor permanente. Obviamente, a presença do sucessor permanente tem a sua influência na velocidade do processo, especialmente no seu início. Isso significa que a rizólise dos dentes decíduos sofre influência de fatores externos ao dente. As radiografias panorâmicas expostas nas figuras 2, 3 e 4 revelam a proximidade entre a odontogênese do canino permanente e a reabsorção fisiológica do canino decíduo. Na população brasileira, o canino permanente superior irrompe, em média, aos 11,5 anos no menino e aos 10,7 anos na menina ${ }^{4}$. Essa contiguidade entre

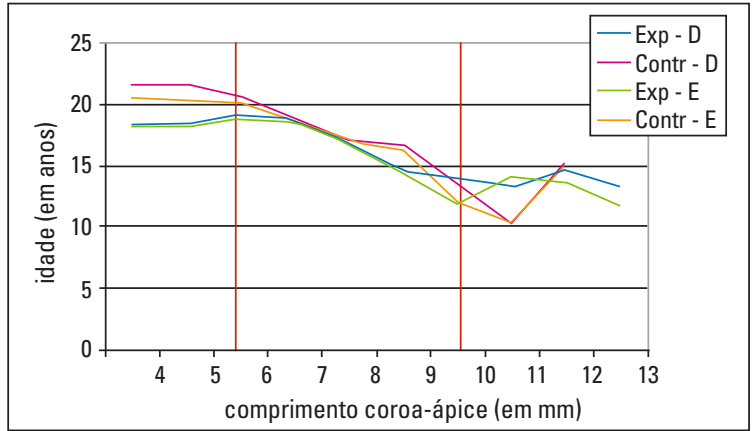

GRÁFICO 1 - Gráfico representativo da velocidade de reabsorção fisiológica dos caninos decíduos superiores dos lados direito e esquerdo, dos grupos experimental (Exp) e controle (Contr).

TABELA 1 - Média (M), desvio-padrão (d.p.) e aplicação do teste "t" de Student para os valores representativos do comprimento dos caninos decíduos superiores, dos lados direito e esquerdo, para os grupos controle e experimental.

\begin{tabular}{|c|c|c|c|c|c|c|c|c|c|c|}
\hline \multirow{3}{*}{$\begin{array}{l}\text { idade } \\
\text { (anos) }\end{array}$} & \multicolumn{5}{|c|}{ lado direito } & \multicolumn{5}{|c|}{ lado esquerdo } \\
\hline & \multicolumn{2}{|c|}{ grupo experimental } & \multicolumn{2}{|c|}{ grupo controle } & \multirow{2}{*}{$\begin{array}{c}\text { teste } \mathrm{t} \\
\mathrm{p}\end{array}$} & \multicolumn{2}{|c|}{ grupo experimental } & \multicolumn{2}{|c|}{ grupo controle } & \multirow{2}{*}{$\begin{array}{c}\text { teste } \mathrm{t} \\
\mathrm{p}\end{array}$} \\
\hline & $\mathrm{M}$ & d.p. & $\mathrm{M}$ & d.p. & & M & d.p. & $\mathrm{M}$ & d.p. & \\
\hline 4 & 18,452 & 2,176 & 21,611 & 2,497 & 0,134 n.s. & 18,225 & 2,007 & 20,602 & 1,951 & 0,178 n.s. \\
\hline 5 & 18,518 & 2,754 & 21,716 & 2,089 & 0,026 sig. & 18,318 & 2,426 & 20,451 & 1,966 & 0,085 n.s. \\
\hline 6 & 19,115 & 2,851 & 20,692 & 2,014 & 0,961 n.s. & 18,842 & 2,641 & 20,192 & 2,115 & 0,135 n.s. \\
\hline 7 & 18,766 & 3,091 & 18,692 & 2,638 & 0,942 n.s. & 18,523 & 2,998 & 18,771 & 2,222 & 0,793 n.s. \\
\hline 8 & 16,811 & 3,181 & 17,135 & 3,548 & 0,767 n.s. & 16,873 & 2,977 & 17,107 & 2,752 & 0,813 n.s. \\
\hline 9 & 14,623 & 3,926 & 16,783 & 2,313 & 0,928 n.s. & 14,385 & 3,846 & 16,203 & 2,233 & 0,146 n.s. \\
\hline 10 & 13,852 & 3,555 & 13,255 & 2,521 & 0,674 n.s. & 11,892 & 4,545 & 12,033 & 3,324 & 0,937 n.s. \\
\hline 11 & 13,383 & 4,759 & 10,321 & 3,011 & 0,245 n.s. & 14,121 & 4,078 & 10,366 & 4,792 & 0,281 n.s. \\
\hline 12 & 14,725 & 3,115 & 15,302 & 0 & 0,879 n.s. & 13,575 & 4,038 & 15,101 & 0 & 0,757 n.s. \\
\hline
\end{tabular}

p: nível de significância a 5\%. 

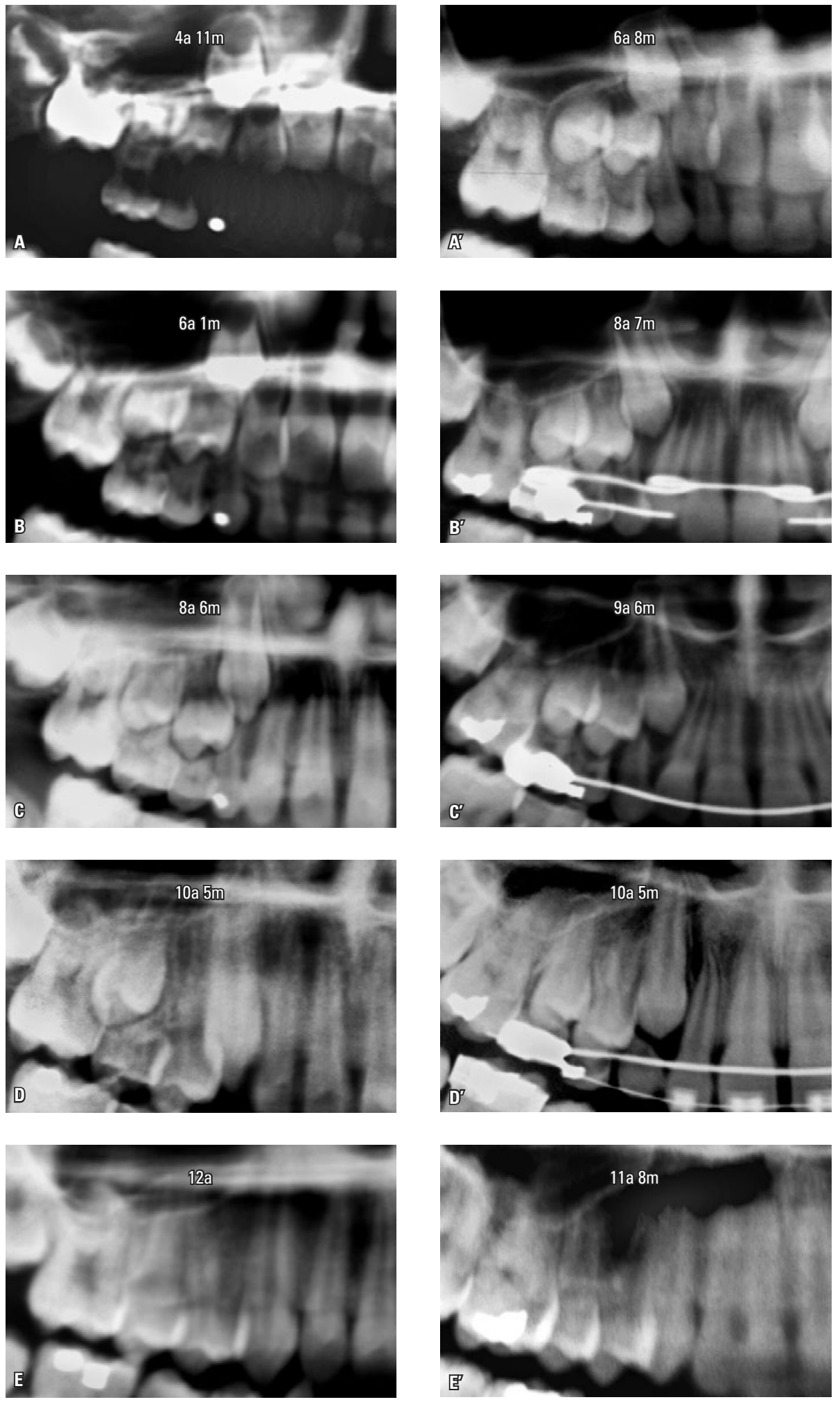

FIGURA 4 - Radiografias panorâmicas de um paciente que se submeteu à ERM (grupo experimental) e um paciente que não se submeteu à ERM (grupo controle). As radiografias estão pareadas com a intenção de comparar o desenvolvimento da dentição (A, B, C, D, E = grupo experimental; A', B', C', D', $\mathbf{E}^{\prime}=$ grupo controle). 
o germe permanente e a rizólise decídua pode levantar dúvidas quanto ao efeito que a ancoragem no dente decíduo pode ter sobre a velocidade da reabsorção fisiológica. Nada foi escrito, até então, sobre a influência que o aparelho expansor ortopédico poderia desempenhar sobre a rizólise dos caninos decíduos e a irrupção dos caninos permanentes. $\mathrm{O}$ presente estudo foi desenvolvido com a intenção de desvendar a influência que a mecânica ortopédica transversal aplicada na dentadura decídua e início da dentadura mista exerce sobre a reabsorção radicular fisiológica dos caninos decíduos.

A figura 4 ilustra o comportamento dos caninos decíduos e permanentes em crianças submetidas ou não à ERM. A comparação entre os dois grupos evidencia a ausência de interferência na velocidade de rizólise dos caninos decíduos. A perda biologicamente programada da raiz decídua não lhes impõe fragilidade; ao contrário, permite-lhes a função de ancoragem promissora. A rizólise dos dentes decíduos parece ser guiada biologicamente por mecanismos genéticos. Inicia-se com a apoptose nos cementoblastos, odontoblastos e restos epiteliais de Malassez ${ }^{3,9}$, seguida pelo povoamento da superfície mineralizada da raiz pelas unidades osteorremodeladoras, ou BMUs. O mecanismo da apoptose funciona como o gatilho biológico da rizólise, assim como também responde pelo desaparecimento da polpa e do ligamento periodontal ${ }^{3}$. Embora o efeito desejado do acionamento do parafuso expansor seja ortopédico, os dentes de ancoragem recebem o impacto da resistência esquelética da face média durante as fases ativa e de contenção. Consequentemente, o aparelho expansor fixo tipo Haas transfere força aos dentes de ancoragem e seu periodonto. $\mathrm{O}$ que isso acarreta aos dentes de ancoragem?

Em geral, a literatura não exclui a possibilidade de influência na polpa de dentes sob impacto da mecânica ortodôntica-ortopédica. No entanto, o comportamento clínico do canino decíduo na presente pesquisa, durante e após a expansão, até a sua esfoliação, denota que a força aplicada ao canino de ancoragem não compromete sua vitalidade pulpar. Não há sintomatologia ou sinais clínicos que sugiram necrose pulpar ou periapicopatias. De fato, o comportamento clínico desses dentes indica não haver alterações significativas na homeostasia celular da polpa. Esse comportamento clínico refere-se à ausência de sintomatologia específica no canino e ao tempo de permanência do canino decíduo na boca ser similar ao do canino controle, sem aparelho (Tab. 1, Gráf. 1). Essas observações clínicas concordam com o conceito de que a movimentação dentária induzida não acarreta dano à polpa ou ao complexo dentinopulpar $^{13,18}$, e concorda com o resultado de análises microscópicas descritivas e morfométricas realizadas em primeiros pré-molares superiores de ancoragem para a ERM na dentadura permanente ${ }^{24}$.

Infere-se, a partir desses dados, que não há rompimento do feixe vasculonervoso constituído pelas arteríolas e vênulas que aportam e saem do forame apical, já que se cogita na literatura a possibilidade de estrangulamento por compressão do feixe vasculonervoso provocado pela força ortodôntica ${ }^{11}$. E, sabidamente, a força da resistência esquelética da face, que se opõe ao acionamento do parafuso expansor, não é pequena ${ }^{6}$. Se houver alteração no fluxo sanguíneo da polpa dentária, ela será insuficiente para provocar alterações com implicações clínicas importantes, como por exemplo a necrose pulpar, e tampouco para influenciar a velocidade de rizólise espontânea dos dentes decíduos. Isso se conclui com base nos resultados visualizados no gráfico 1 .

Alterações pulpares tais como congestão ${ }^{14,16,28}$, aumento do número de vasos funcionais ${ }^{16}$, hiperemia, trombose e hemorragia podem fazer parte do processo inflamatório diagnosticado por alguns autores ${ }^{14}$, inclusive envolvendo necrose pul$\operatorname{par}^{11,12,27}$ quando da liberação de forças ortodônticas sobre os dentes.

A superfície radicular externa responde com reabsorção ao estresse provocado no ligamento periodontal pelas forças ortodônticas. Esse fato 
é bem reconhecido pelos ortodontistas como reabsorção radicular externa apical, passível de ser identificada na imagem da radiografia periapical em todos os dentes movimentados ortodonticamente. Os trabalhos histológicos também têm demonstrado que a reabsorção radicular externa está presente nos dentes de ancoragem submetidos à $\mathrm{ERM}^{8,25,26}$. Essa reabsorção é indetectável na imagem radiográfica periapical, a qual é bidimensional e mascara as superfícies vestibular e lingual, e também devido à magnitude da reabsorção radicular. Por isso, o exame radiográfico periapical não denuncia a reabsorção radicular nos primeiros pré-molares que ancoram o aparelho expansor tipo Haas na dentadura permanente. A atividade reabsortiva nos primeiros pré-molares de ancoragem mostra um processo ativo de reabsorção imediatamente após a expansão ${ }^{24}$ e uma reabsorção reparada com deposição de cemento celular após a fase de contenção com o aparelho expansor cimentado na boca ${ }^{16,24}$. A metodologia aplicada na presente pesquisa, radiografia panorâmica, não permite diagnosticar a reabsorção na superfície radicular dos caninos decíduos. Contudo, possibilita a visualização do encurtamento radicular progressivo e fisiológico. A reabsorção radicular causada pela mecanoterapia pode levar o ortodontista a extrapolar os dados para os dentes decíduos. Quando recebem forças geradas por dispositivos mecânicos, as raízes decíduas podem ter sua reabsorção fisiológica antecipada ou acelerada. No entanto, não é o que ficou demonstrado na presente pesquisa com os caninos decíduos. A velocidade de rizólise dos caninos decíduos foi semelhante nos dois grupos de pacientes estudados, o grupo controle e o grupo submetido ao aparelho expansor fixo tipo Haas.

\section{CONCLUSÃO}

Os dados estatísticos nos conduzem a ressaltar o fato assistido e comprovado clinicamente, ainda não devidamente enfatizado nos meios acadêmi$\cos$, da independência e superioridade da rizólise dos caninos decíduos em relação à mecanoterapia ortodôntica.

\title{
Influence of rapid maxillary expansion on the root resorption of primary canines used as anchorage
}

\begin{abstract}
Aim: The current radiographic, retrospective longitudinal study aim was to demonstrate whether the Haas fixed appliance, modified for the primary and mixed dentitions, interferes in the velocity of the root resorption and exfoliation of the primary canines. Methods: It was evaluated the amount of root resorption of primary canines on the basis of measurements of the apex-crown length of right and left upper primary canines. For this measurement twenty-four children submitted to rapid maxillary expansion (RME) in the primary and mixed dentition were compared to 15 children who did not undergo such a procedure. The measurement of the apex-crown length of the primary canines was achieved with the CEF-X program that allowed the calibration and standardization of the image size. Results: Statistical data revealed that no difference was found in the velocity of root resorption of the primary canines between the control and experimental groups. Conclusions: The findings of this study allow us to conclude that root resorption of primary canines has no relationship with RME.
\end{abstract}

Keywords: Maxillary expansion. Malocclusion. Root resorption. Orthodontics, Interceptive. 


\section{REFERÊNCIAS}

1. ADKINS, M. D.; NANDA, R. S.; CURRIER, G. F. Arch perimeter changes on rapid palatal expansion. Am. J. Orthod. Dentofacial Orthop., St. Louis, v. 97, no. 3, p. 194-199, Mar. 1990.

2. BARBER, A. F.; SIMMS, M. R. Rapid maxillary expansion and external root resorption in man: A scanning electron microscope study. Am. J. Orthod., St. Louis, v. 79, no. 6, p. 630-652, June 1981.

3. CONSOLARO, A. Reabsorções dentárias nas especialidades clínicas: Ortodontia, Endodontia, Odontopediatria, Cirurgia e Traumatologia, Periodontia e Prótese, Radiologia, Dentística, Patologia, Implantodontia. Maringá: Dental Press, 2002.

4. FREITAS, J. A. S.; LOPES, E. S.; ALVARES, L. C.; FREITAS, P. Z. Variabilidade das fases de formação e erupção dos dentes permanentes. Ortodontia, São Paulo, v. 23, n. 2, p. 29-39, maio/ago. 1990.

5. HAAS, A. J. Rapid expansion on the maxillary dental arch and nasal cavity by opening the midpalatal suture. Angle Orthod., Appleton, v. 31, no. 2, p. 73-90, Apr. 1961

6. ISAACSON, R. J.; INGRAM, A. H. Forces produced by rapid maxillary expansion. II. Forces present during treatment. Angle Orthod., Appleton, v. 34, no. 4, p. 261-270, Oct. 1964.

7. KAYAN, F.; KÜÇÜKKELES, N.; DEMIREL, D. A histologic and histomorphometric evaluation of pulpal reactions following rapid palatal expansion. Am. J. Orthod. Dentofacial Orthop. St. Louis, v. 117, no. 4, p. 465-473, Apr. 2000.

8. LANGFORD, S. R. Root resorption extremes resulting from clinical RME. Am. J. Orthod., St. Louis, v. 81, no. 5, p. 371-377, May 1982.

9. LOURENÇO, S. Q. C.; CONSOLARO, A. Apoptosis in odontogenesis: Dental lamina, Hertwig's epithelial sheath and reduced ameloblasts. J. Dent. Res., Chicago, v. 76 p. 120, 1997. Special issue. Abstract n. 855.

10. MACHADO, A. W.; SOUKI, B. Q. Simplificando a obtenção e a utilização de imagens digitais: scanners e câmeras digitais. R. Dental Press Ortodon. Ortop. Facial, Maringá, v. 9, n. 4, p. 133-156, jul./ ago. 2004

11. MARSHALL, J. A. A study of bone and tooth changes incident to experimental tooth movement and its application to orthodontic practice. Int. J. Orthod. Dent. Child., [S.I.], v. 19, no. 1, p. 1-17, 1933.

12. McDONALD, F.; PITT-FORD, T. R. Blood flow changes in permanent maxillary canines during retraction. Eur. J. Orthod., Oxford, v. 16, no. 1, p. 1-9, Feb. 1994

13. MELSEN, B. Tissue reaction following application of extrusive and intrusive forces to teeth in adult monkeys. Am. J. Orthod., St. Louis, v. 89, no. 6, p. 469-475, June 1986

14. MOSTAFA, Y. A.; ISKANDER, K. G.; EL-MANGOURY, N. H. latrogenic pulpal reactions to orthodontic extrusion. Am. J. Orthod. Dentofacial Orthop., St. Louis, v. 99, no. 1, p. 30-34, Jan. 1991.

15. NGAN, P. W.; WEI, S. H. Y. Treatment of posterior crossbite in the primary and early mixed dentitions. Quintessence Int., Berlin, v. 21, no. 6, p. 451-459, June 1990.

16. NIXON, C. E.; SAVIANO, J. A.; KING, G. J.; KEELING, S. D. Histomorphometric study of dental pulp during orthodontic tooth movement. J. Endod., New York, v. 19, no. 1, p. 13-16, Jan. 1993.

17. ODENRICK, L.; LILJA, E.; LINDBÄCH, K. F. Root surface resorption in two cases of rapid maxillary expansion. Br. J. Orthod., Oxford, v. 9, no. 1, p. 37-40, Jan. 1991

18. POPP, T. W.; ARTUN, J.; LINGE, L. Pulpal response to orthodontic tooth movement in adolescents: A radiographic study. Am. J. Orthod. Dentofacial Orthop., St. Louis, v. 101, no. 3, p. 228-233, Mar. 1992.

19. SILVA FILHO, O. G.; CAPELLOZA FILHO, L. Expansão rápida da maxila: preceitos clínicos. Ortodontia, São Paulo, v. 21, n. 1, p. 61-81, jan./jun. 1988.
20. SILVA FILHO, O. G.; FERRARI JUNIOR, F. M.; AIELLO, C. A.; ZOPONE, N. Correção da mordida cruzada posterior na dentadura decídua. Ortodontia, São Paulo, v. 32, n. 3, p. 60-68, set./dez. 1999.

21. SILVA FILHO, O. G.; FREITAS, P. Z.; SILVA, V. B. Aparelho expansor fixo dentomucossuportado: considerações clínicas sobre a mucosa palatina. Rev. Clín. Ortodon. Dental Press Maringá, v. 3, n. 1, p. 57-63, fev./mar. 2004.

22. SILVA FILHO, O. G.; HERNANDES, R.; OKADA, T. Efeitos induzidos pela expansão rápida da maxila sobre os prémolares de ancoragem: estudo radiográfico. Ortodontia, São Paulo, v. 27, n. 3, p. 18-36, set./dez. 1994.

23. SILVA FILHO, O. G.; VILLAS BOAS, M. C.; CAPELLOZA FILHO, L. Rapid maxillary expansion in the primary and mixed dentitions: A cephalometric evaluation. Am. J. Orthod. Dentofacial Orthop., St. Louis, v. 100, no. 2 p. 171-179, Aug. 1991.

24. VALLADARES NETO, J. Análise do complexo dentinopulpar e da superfície radicular externa após a expansão rápida da maxila em adolescentes. 2000. Dissertação (Mestrado)Instituto de Ciências Biológicas, Universidade Federal de Goiás, Goiânia, 2000.

25. VARDIMON, A. D.; GRABER, T. M.; PITARU, S. Repair process of external root resorption subsequent to palatal expansion treatment. Am. J. Orthod. Dentofacial Orthop., St. Louis, v. 103 , no. 2, p. 120-130, Feb. 1993

26. VARDIMON, A. D.; GRABER, T. M.; VOSS, L. R.; LENKE, J. Determinants controlling iatrogenic external root resorption and repair during and after palatal expansion. Angle Orthod., Appleton, v. 61, no. 2, p. 113-122, Summer 1991.

27. WOLOSHYN, H.; ARTUN, J.; KENNEDY, D. B.; JOONDEPH, D. R. Pulpal and periodontal reactions to orthodontic alignment of palatally impacted canines. Angle Orthod. Appleton, v. 64, no. 4, p. 257-264, Aug. 1994.

28. WONG, V. S.; FREER, T. J.; JOSEPH, B. B.; DALLEU, T. J. Tooth movement and vascularity of the dental pulp: A pilot study. Aust. Orthod. J., Brisbaine, v. 15, no. 4, p. 246-250, Apr. 1999
Endereço para correspondência

Omar Gabriel da Silva Filho

Rua Sílvio Marchione, 3-20 - Vila Universitária

CEP: 17.043-900 - Bauru / SP

E-mail: ortoface@travelnet.com.br 